\title{
Keep up the identification and management of common temporary epicardial pacing following cardiac surgery pitfalls the prevention, pace: the NER *
}

Majella Hales, RN; BN, M App Sci, Lecturer, School of Nursing, Australian Catholic University, Brisbane, Australia

E-mail: m.hales@mcauley.acu.edu.au

Key words: lead microshock pacemaker pacing safety troubleshooting wire

\section{SUMMARY \\ * Epicardial pacing is common in the immediate post-operative period following cardiac surgery. \\ * $\quad$ Problems associated with temporary epicardial pacing may expose patients to potentially fatal complications. \\ * Contemporary intensive care unit nurses need a working knowledge and understanding of pulse generators and settings. \\ * The common problems are outlined to clearly demonstrate their prevention, identification and management following cardiac surgery.}

\section{INTRODUCTION}

The use of epicardial pacing wires following cardiac surgery is common practice in the prevention or treatment of arrhythmia. Trauma from the surgery can lead to septal swelling that could have an impact on the conduction system (Chung, 2000). Metabolic disorder and electrolyte imbalance could also be another cause of arrhythmia. Prevention or control of arrhythmia can often be achieved by having epicardial wires in place so they are conveniently available if and when the need arises. This article focuses on the common causes of equipment 'failing to pace' in epicardial pacing.

\section{BACKGROUND}

As pacing enters its fifth decade of existence (Medtronic, 2004), the need for nursing knowledge associated with the use of pacing increases. Failure of any of the components in a temporary pacing unit can prove fatal. Pacemaker dependent patients are most at risk. Despite the importance of establishing practices to prevent failure, occasionally a nurse may still be faced with situations that require rapid identification and correction of a pacemaker problem.

\section{COMPONENTS}

An epicardial pacing system consists of three main components: a pulse generator, one or two leads, and two or four epicardial wires (Figure 1). The electrical unit that generates an impulse to be delivered to the myocardium is called the pulse generator or pacing box. It is the functional part of the whole unit and the settings enable the cardiac surgical team to achieve precise control over the patient's rhythm. Pulse generators can be described as single-chamber or dual-chamber. Single-chamber pulse generators can only pace either the atria or the ventricles. Dual-chamber pulse generators are capable of pacing both the atria and the ventricles.

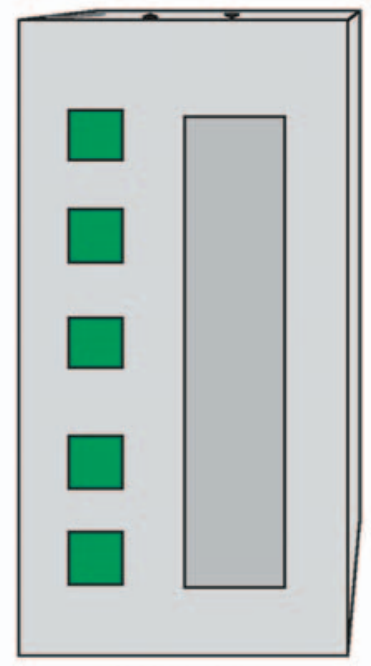

Pulse generator
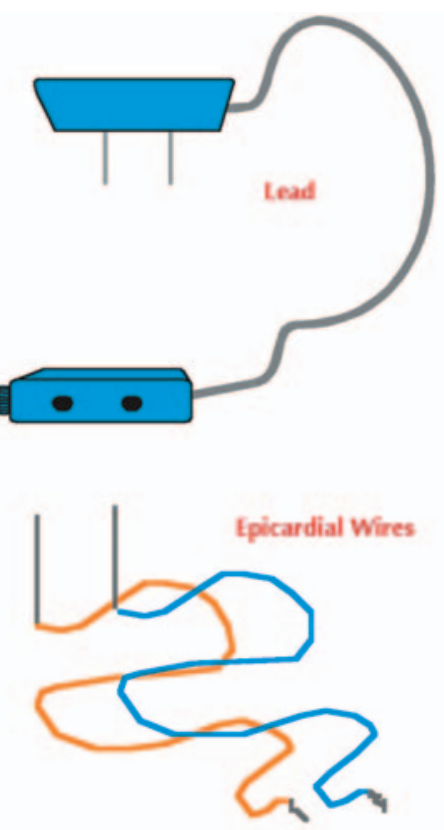

Figure 1: Epicardial pacing components in a single-chamber pulse generator

The cabling that carries the impulse from the generator to the epicardial wire is called the lead or bridging cable (Figure 1). A single-chamber pacemaker needs one cable and a dual-chamber needs two (one atrial lead and one ventricular lead). Attached to the lead are the cables that carry the impulse from the lead to the myocardium. These are called epicardial wires (Figure 1). Temporary epicardial pacing requires two wires per lead. The elec- 
trical current generated by the pacing box flows in a closed loop between the two poles. One wire acts as a cathode (negative pole) and the other as an anode (positive pole). The current flows down the cathode and returns through the anode. The myocardium acts as the conductive material between the two wires.

\section{USE}

Changes in the cardiac myocytes, due to inflammation following the trauma of surgery, can affect the patient's conduction system. Injury to the conduction system may also affect the patient's cardiac rhythm and cause various forms of arrhythmia including asystole. When temporary epicardial pacing is inserted following cardiac surgery, the intensive care team can often prevent or control these difficulties.

\section{THREE-LETTER PACEMAKER CODES}

With numerous programming possibilities available, there is a rapid, universal method of program description. Table 1 summarises some common epicardial pacing settings. Pacing can be described as demand or asynchronous. In demand pacing, the pulse generator senses an intrinsic event and stops a pulse being generated. In asynchronous mode, there is no sensing of the intrinsic rate. As demonstrated in Table 1, the pacing box generates an impulse at the set rate and delivers it to the implanted location, whether the patient has a rhythm or not.

Care of a paced patient requires deeper knowledge and understanding of pacing concepts. The rest of this article focuses on pacing pitfalls. For further information on pacing basics, consult Jacobson and Gerity (2005) or Irwin (2004).

\section{SIGNIFICANCE}

The outcome for a patient will depend on a number of variables including: the patient's reliance on the pacing unit, the type of problem and the speed at which the nurse can identify and rectify the problem. If a patient is pacemaker dependant, the situation is critical and may require the use of transcutaneous pacing or drugs such as atropine to palliate the patient and allow time for diagnosing the problem.

Equipment-related pacing pitfalls can be divided into four distinct problems. These problems can be associated with the pulse generator, lead or wire. Three 'other problems' identified here are not failure of the equipment per se; rather, they are situations related to the misuse of the pacing equipment that could lead to problems for the patient. Figure 2 summarises the common equipment-related pacing pitfalls.

\begin{tabular}{|c|c|c|c|c|c|}
\hline & Setting & $\begin{array}{l}\text { First letter: } \\
\text { chamber paced }\end{array}$ & $\begin{array}{l}\text { Second letter: } \\
\text { chamber sensed }\end{array}$ & $\begin{array}{l}\text { Third letter: } \\
\text { response to } \\
\text { sensing }\end{array}$ & Comment \\
\hline \multirow{3}{*}{ 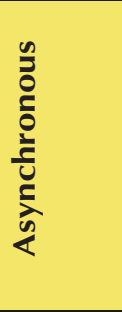 } & $\mathrm{AOO}$ & Atrial & None & None & \multirow{3}{*}{$\begin{array}{l}\text { Asynchronous pacing modes do not sense any intrinsic } \\
\text { event. These modes are safest for individuals with severe } \\
\text { bradycardia or no intrinsic events. An intrinsic rate } \\
\text { approximating the programmed rate may cause competition } \\
\text { between the box and the patient. This scenario may lead to } \\
\text { an 'R on T' episode in the ventricles, or equivalent in } \\
\text { the atria. }\end{array}$} \\
\hline & VOO & Ventricular & None & None & \\
\hline & DOO & $\begin{array}{l}\text { Atrial \& } \\
\text { Ventricular }\end{array}$ & None & None & \\
\hline \multirow{2}{*}{ 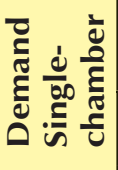 } & AAI & Atrial & Atrial & Inhibit & \multirow{4}{*}{$\begin{array}{l}\text { Demand pacing modes are safer than asynchronous because } \\
\text { they are responsive to intrinsic events, therefore pacing on a } \\
\text { need basis is achieved. If the intrinsic rate falls below the } \\
\text { programmed rate, the box will trigger an impulse. } \\
\text { Demand dual-chamber pacing is the best mode to harness } \\
\text { the benefits of the atrial kick. Sequential pacing, sensing } \\
\text { atrial and ventricular events, will promote appropriate timing } \\
\text { with less risk of competition. Sequential pacing is not } \\
\text { possible with sensed ventricular pacing (VVI). }\end{array}$} \\
\hline & VVI & Ventricular & Ventricular & Inhibit & \\
\hline \multirow[b]{2}{*}{ 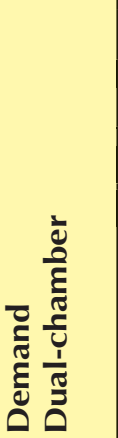 } & DVI & $\begin{array}{l}\text { Atrial \& } \\
\text { Ventricular }\end{array}$ & Ventricular & Inhibit & \\
\hline & DDD & $\begin{array}{l}\text { Atrial \& } \\
\text { Ventricular }\end{array}$ & $\begin{array}{l}\text { Atrial \& } \\
\text { Ventricular }\end{array}$ & $\begin{array}{l}\text { Inhibit or } \\
\text { Trigger }\end{array}$ & \\
\hline
\end{tabular}

Table 1: Common epicardial pacing settings. 


\section{Equipment Related Pacing Pitfalls}

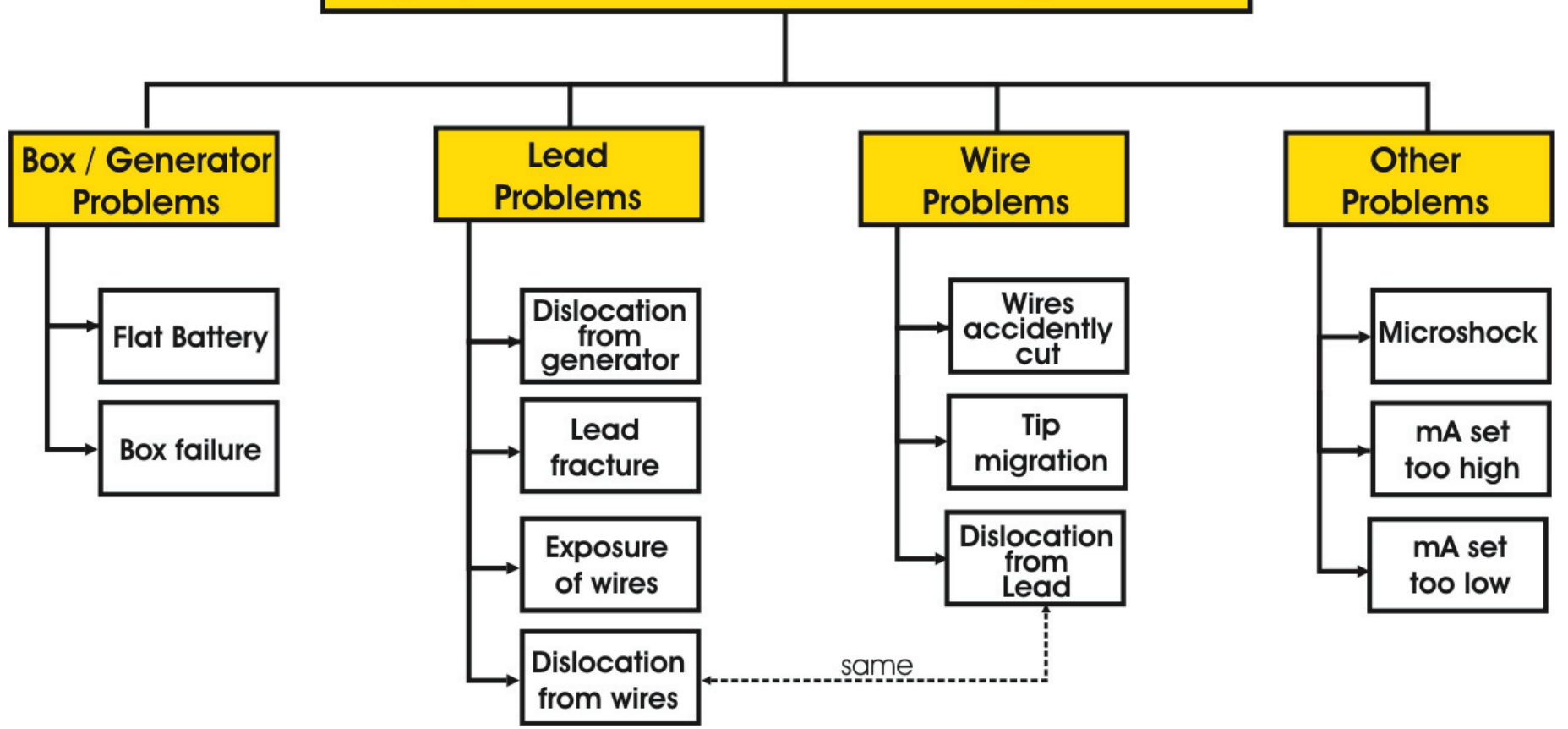

Figure 2: Common equipment-related pacing pitfalls.

\section{PACING PITfALlS}

Box/generator problems

Pulse generator or box problems can cause catastrophic failure. This can be prevented by educating staff so that they are familiar with the pulse generator to enable rapid battery changes, through to recognising important symbols that might be displayed. The red oval in Figure 3 identifies the source of the failure in this instance.

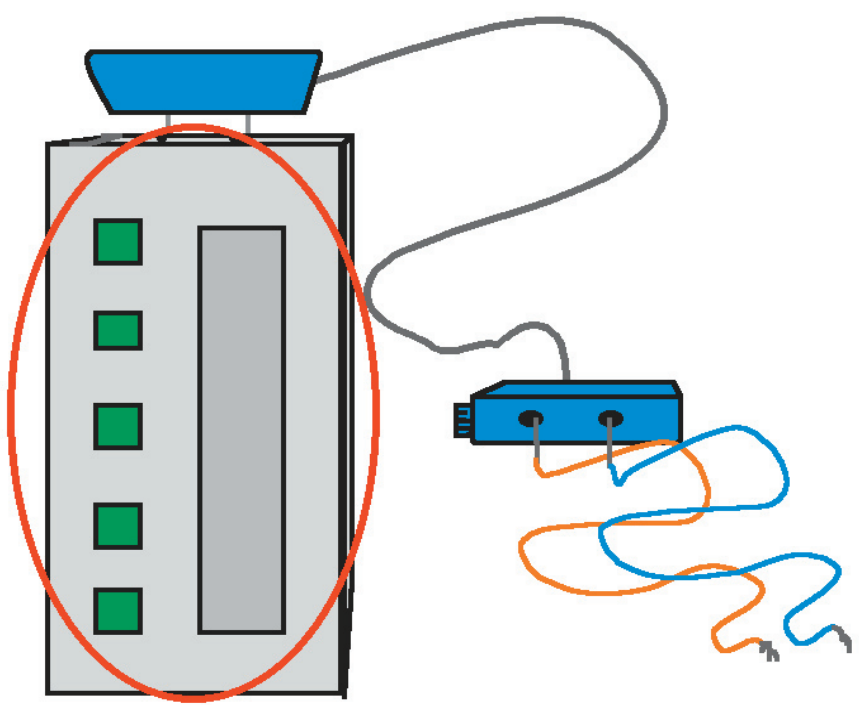

Figure 3: Box problems.

\section{Prevention}

Routine observations in an intensive care setting should include checking that the pacing box mode and rate are correctly programmed and that the connections are intact. Although box failure from circuit board damage or some other internal component malfunction is difficult to prevent, regular servicing and taking care not to drop the unit will help avoid this.

\section{Scenario}

In a cardiac surgical intensive care unit (ICU) where insufficient pacing box carriers were available, it was common practice to use adhesive surgical tape to hang the pacing boxes from the intravenous (IV) poles. This unsafe practice resulted in a number of generators dropping to the floor as the surgical tape gave way. Following review of this practice, the hospital's sewing room was contracted to make material bags in which the boxes could be hung.

Recognising a 'low battery' alert will increase the time available before ultimate box failure. When pacing boxes have a liquid crystal display (LCD), an image of a battery will appear. Figure 4 demonstrates an example of the image that is displayed on the Medtronic 5346 DDD Temporary Pulse Generator (Medtronic Inc., Minneapolis, MN).

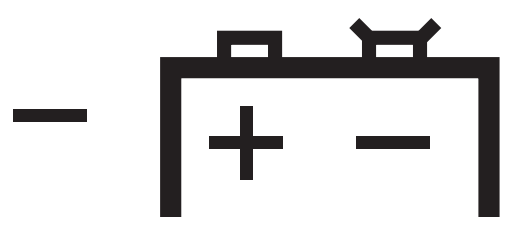

Figure 4. Low battery alert.

Pacing boxes without LCD displays often have a light on the front panel as the low battery indicator. It is worth consulting the equipment specification literature that comes with the unit to find out what the standard battery life is for the type used at your institution (e.g. alkaline or lithium). Figure 5 summarises these issues. 


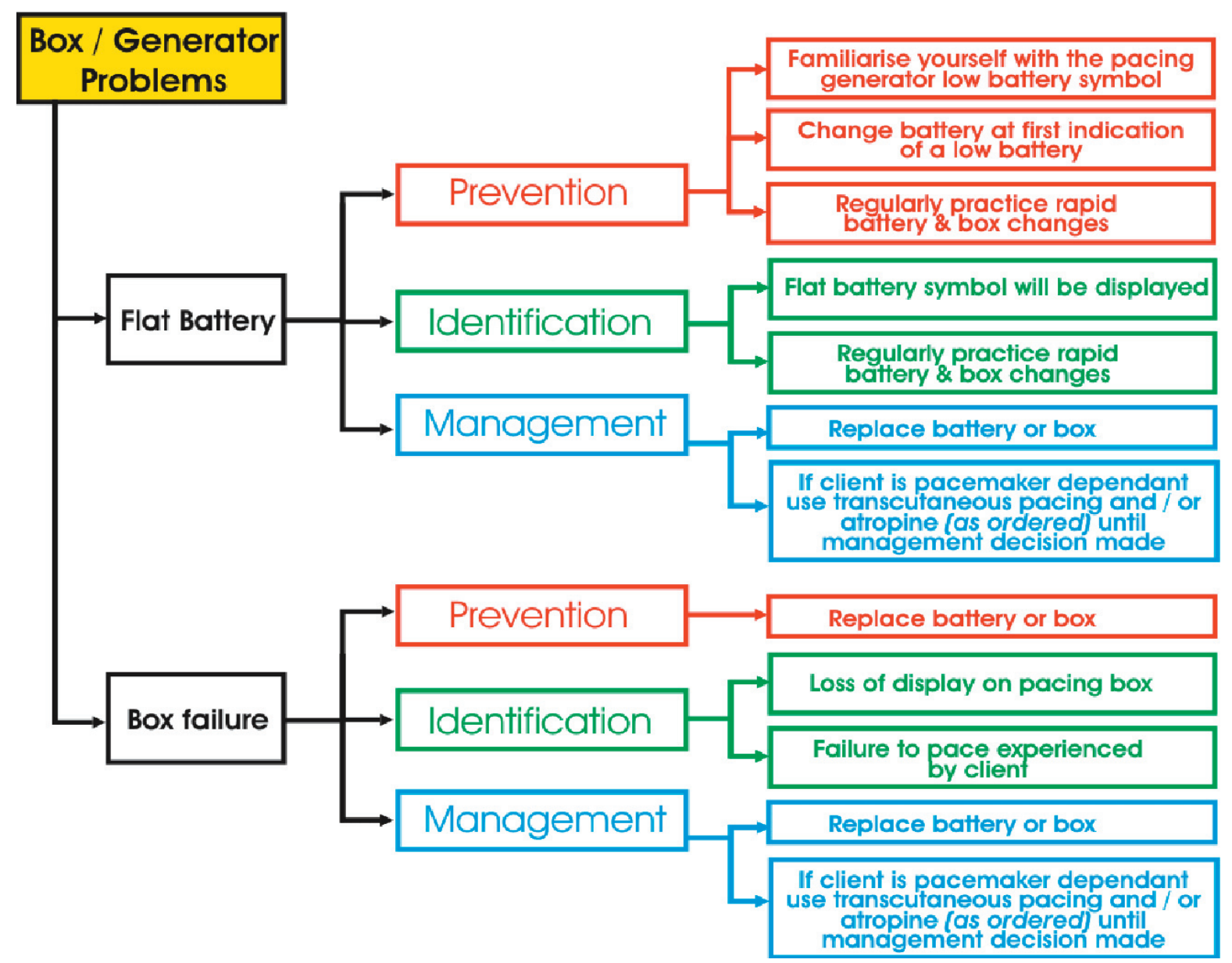

Figure 5: Summary of box problems.

\section{Identification}

If the 'low battery' indicator is not seen, pacing box problems can be identified by the rapid haemodynamic decline of pacemaker dependant patients. With generator problems caused by a flat battery, there will be sufficient time from when the 'low battery' indicator appears to change the unit and/or battery. A spare battery should be kept close at hand and another generator could be kept on the emergency/resuscitation trolley.

\section{Scenario \\ In a cardiac surgical ICU where an external pacing box with a slightly cracked $L C D$ was not replaced, the low battery alert indicator was obscured. This resulted in the nurse failing to notice that the battery was flat. Fortunately, the pacing was set on DDD at 70bpm and the patient was in sinus rhythm at approximately $82 \mathrm{bpm}$. On inspection of the box at handover, it was noticed that the display was lost as the box had turned off.}

\section{Management}

When generator/box problems occur, the priority is to (re)secure haemodynamic stability. The use of drugs to increase rate (e.g. atropine or adrenaline) or transcutaneous pacing may be needed and, ultimately, the generator or battery should be changed. Practising battery changes in non-emergency times will help ICU nurses in emergency situations.

\section{Lead problems}

Lead problems associated with either fracture or dislocation (disconnection) may result in variable patient outcomes. Immediate inability to pace will be experienced with dislocation (or disconnection) from either the generator or wires. However, intermittent failure to pace or failure to sense may be experienced with lead fracture. The red arrows in Figure 6 identify possible sources of the failure in this instance.

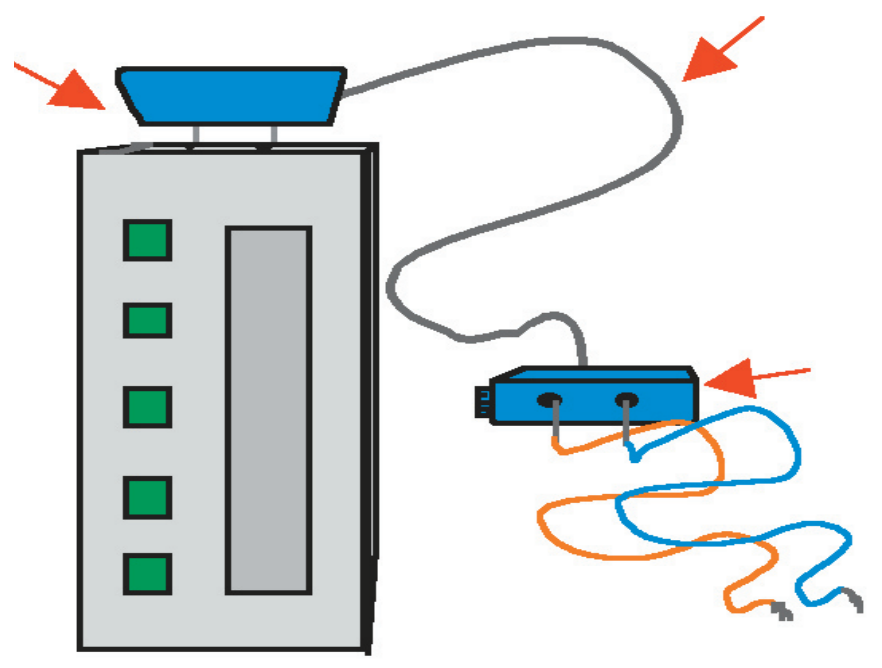

Figure 6: Possible sources of lead failure. 
* Keep up the pace: the prevention, identification and management of common temporary epicardial pacing pitfalls following cardiac surgery*

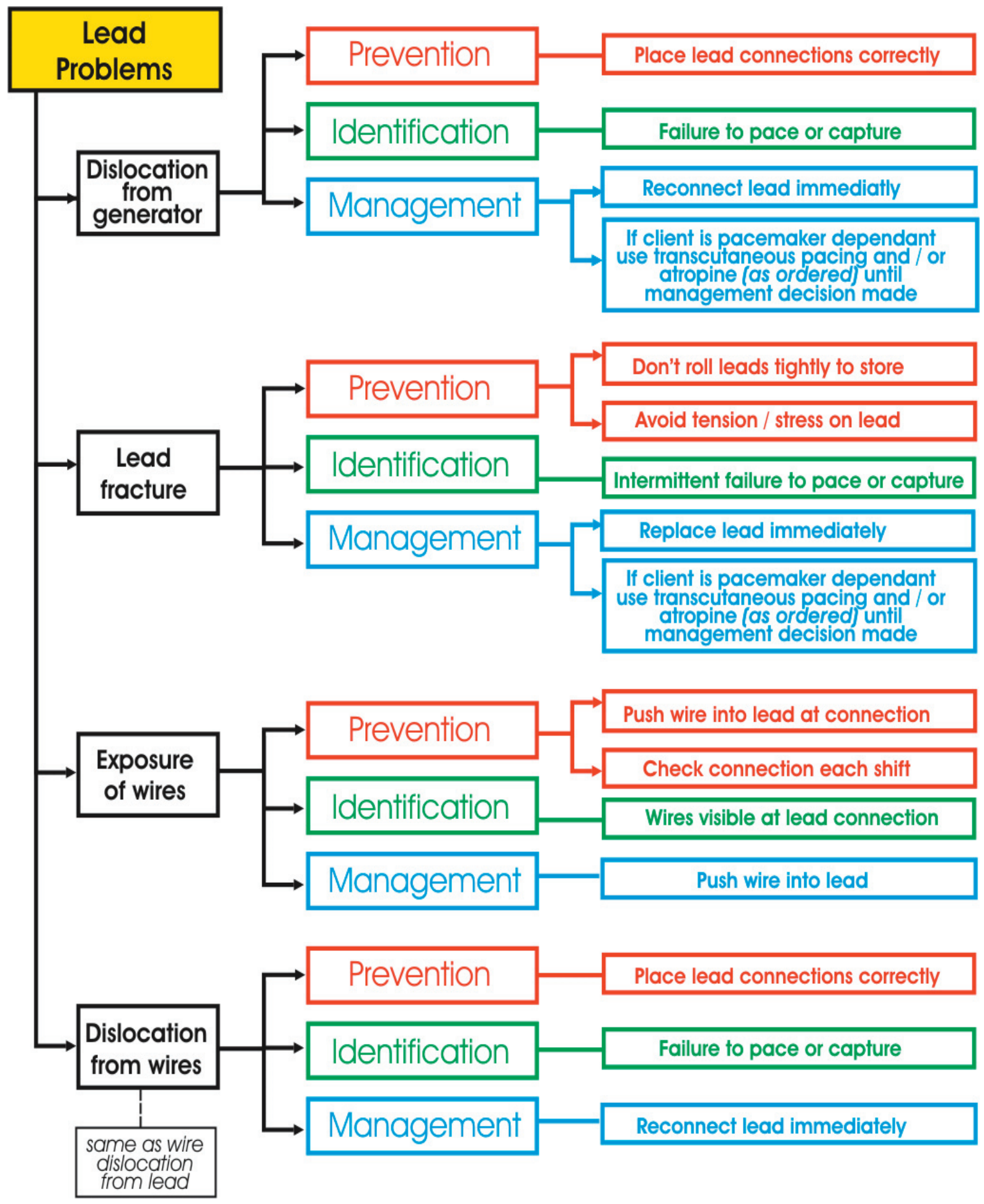

Figure 7: Summary of lead problems. 


\section{Scenario}

In a cardiac surgical ICU, pacing problems were experienced with a patient every time pressure area care (PAC) was performed. The pacing was set on AAI at 80bpm. The patient had an intrinsic sinus rate of approximately $64 \mathrm{bpm}$. During the $P A C$, the nursing staff would observe failure to pace, and on immediate repositioning (to the patient's previous position) when pacing was lost, the staff would observe AAl at $80 \mathrm{bpm}$. Through a process of elimination after examining the connections and failing to find an issue, the lead was changed and no pacing difficulties occurred again. The lead felt irregular, like false knots in an umbilical cord.

\section{Prevention}

Lead problems can be prevented by ensuring that all connections are correctly and tightly screwed or clamped. Some institutions place adhesive tape over the connections, although the benefit of this is debatable and may impede a rapid lead or generator change if required. Correct storage of the leads will preserve their life. Tight coiling of any lead will potentially cause fracturing of the wire inside the lead. The product distributors should be able to give advice on storage and handling practices.

Although exposure of wires will cause no immediate problem, there is the potential for microshock (discussed later in this article) and so steps to rectify this should be taken immediately.

\section{Identification}

At the onset of this problem, intermittent or total failure to sense or failure to pace will be seen on the monitor and the patient's haemodynamic stability may be compromised. For correct problem diagnosis, it is important to differentiate between failure to pace and failure to capture. Failure to pace (Figure 8) could be a sensing problem or a disconnection problem. However, with failure to capture (Figure 9), the impulse travels down the appropriate path but is not strong enough (or is in the wrong position) to initiate a response from the myocardium.

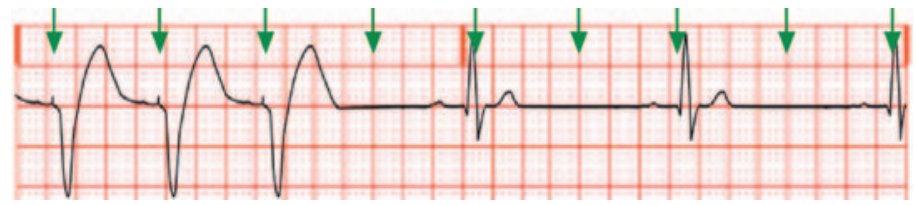

Figure 8: Failure to pace.

This example (Figure 8) demonstrates three ventricular paced complexes followed by the remaining rhythm strip without pacing spikes. This is an example of failure to pace and could be the result of a lead being disconnected from the generator or a wire from the lead.

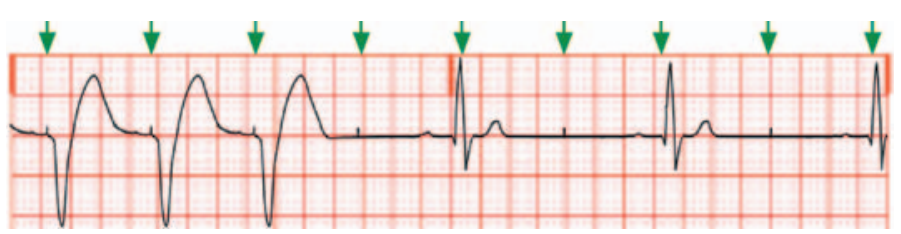

Figure 9: Failure to capture.

This example (Figure 9) shows three ventricular paced complexes followed by asynchronous pacing spikes occurring repeatedly as programmed (without sensing the intrinsic rate). This example of failure to capture could be the result of insufficient $\mathrm{mA}$ or tip migration out of the ventricular myocardium.

\section{Management}

As in all situations, blood pressure control is imperative. If the patient is not rate dependant, there is more time to problem solve. It may be useful to connect a new set of leads and generator, reproduce the pacing settings and change the whole unit. If this does not rectify the problem, the issue is not with the lead or the pacing box. Other methods of rate and rhythm control will be necessary. If changing the unit fixed the problem, sending the unit to the hospital's technical department would ensure that it is safely out of use and able to be tested and either repaired or replaced.

To manage exposure of wires, put on a glove and use the normal procedure for connecting the wire to a lead to push the wire deeper into the lead.

\section{Scenario}

In a cardiac surgical ICU, a nurse noticed that the ventricular wires were exposed at the lead connection. Knowing this was a potential danger, without applying gloves, the nurse pushed the wires deeper into the lead. The paced patient immediately experienced an ' $R$ on $T$ ' episode and went into ventricular tachycardia which rapidly progressed to ventricular fibrillation. The patient was successfully resuscitated. See microshock (below) for more information on this situation.

\section{Wire Problems}

The three distinct difficulties encountered with the wire can be characterised as: disconnection from lead (which is the same as the lead disconnecting from the wire - addressed above), accidental cutting of wires, and tip migration. Figure 10 demonstrates the potential location of common wire problems.

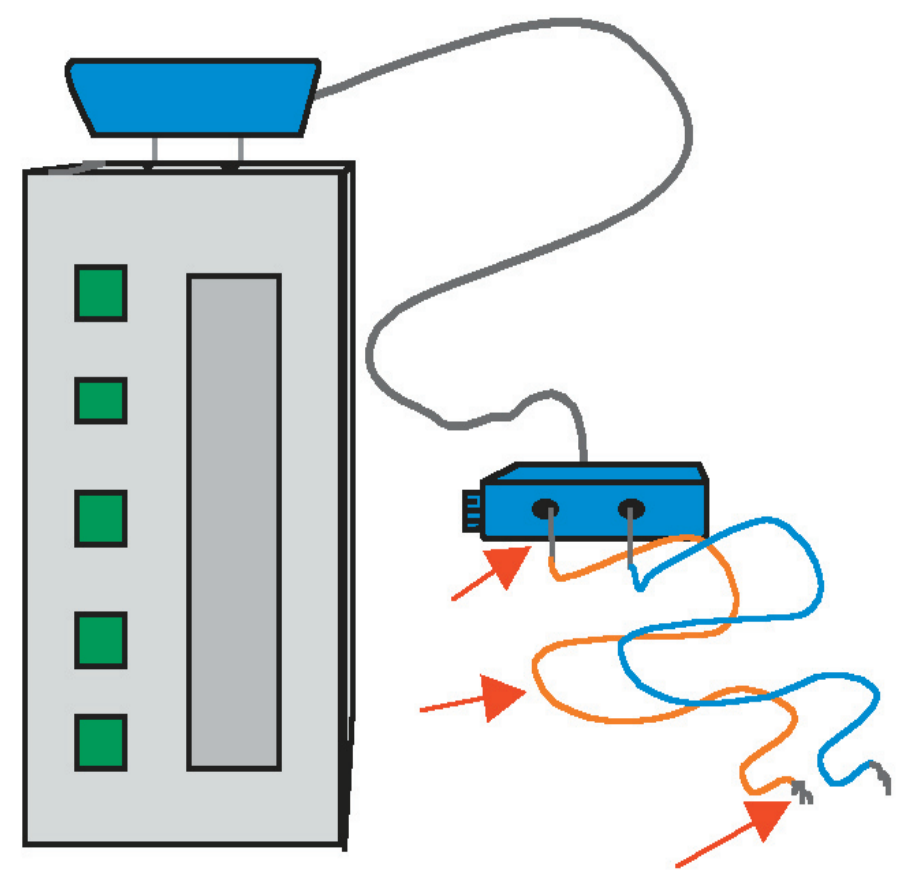

Figure 10: Wire problems. 
Knowledge of whether atrial or ventricular wires are involved may help the nurse to predict the possible outcomes. Although it is usual to place the atrial wires through the chest wall and out of the skin to the right of the sternum, and ventricular wires to the left, there may be variations on this depending on the individual surgeon. Figure 11 summarises the common wire problems

\section{Prevention}

Instances of inadvertently cutting the pacing wire have been reported anecdotally, and occasionally in the literature (Hurle et al., 2002). Depending on the location of the epicardial wires and the standard protocol for mediastinal wound dressing and chest drain placement, when wires are nearby there is the risk of accidentally severing one or both of the wires when removing the chest drain. However, isolating the wires and separating them from the sutures or purse-string should be done before removing the chest drain or using a stitch cutter near the wires.
'Tip migration' is when the tip of the epicardial pacing wire moves from its initial point of insertion. Although difficult to prevent, care during patient repositioning may help. Theoretically, an epicardial pacing wire tip could migrate to anywhere in the thoracic or abdominal cavity.

\section{Identification}

In all three examples of wire problems, there will be loss of pacing, so supportive measures will be needed if the patient is pacemaker dependant. If the patient is not pacemaker dependant, tip migration may not be obvious. However, diaphragmatic pacing from ventricular wires can be easily identified. In the ventilated patient, there will be high peak pressures and a synchrony of the pacing rate with pulsation on the pressure gauge. The patient may also report chest pain and, if non-ventilated, there may be hiccupping with every monitored pacing spike.
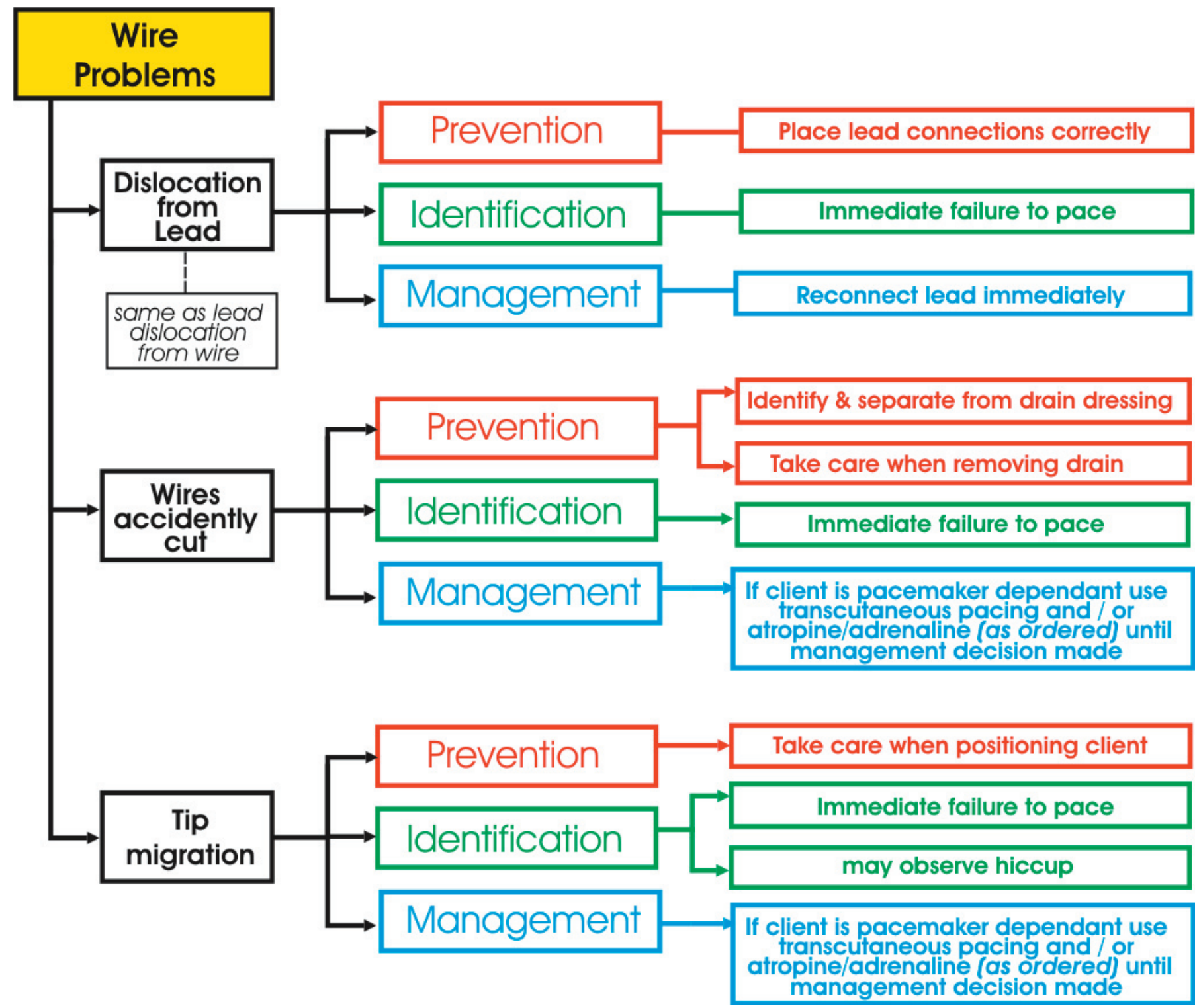

Figure 11: Summary of wire problems. 
Although no specific statistics quantify the frequency of epicardial wire tip migration, Toquero et al. (2003) identified that the lead displacement rate in implanted pacemakers was between $1 \%$ and $5.2 \%$. Also, according to Jefferies et al. (2005), the continual movement from the contracting heart or torque may cause the tip to move.

\section{Scenario \\ In a cardiac surgical ICU, a nurse was removing the mediastinal chest drain. The nurse had removed the dressing, swabbed, and was about to cut the drain suture when another nurse, who had approached the bed, stepped away. The long pacing lead got caught in her stethoscope and the stress on the epi- cardial wire pulled it through the tethering suture and out by several centimetres. Although the patient was not pacemaker dependant, he experienced an adverse outcome, as several hours later, he developed a tamponade which required chest re-opening in theatre.}

\section{Management}

Again, a method to palliate rate will be required if haemodynamic stability is lost due to bradycardia/asystole. Immediate consultation with the medical staff is needed and a management decision should be made. If the patient is not pacemaker dependant, and has a sufficiently low threat of arrhythmia, the team may decide not to replace the wires. Alternatively, transcutaneous or transvenous wires may be used.

\section{Miscellaneous problems}

Microshock and inappropriate $\mathrm{mA}$ settings are almost always preventable and basic practices can protect patients from this experience. Microshock is when an electrical current passes directly into the myocardium. Epicardial wires bypass the skin's protective resistance and enable current generated from static electricity to be delivered directly into the myocardium with the potential to cause fibrillation. Figure 12 summarises the common wire problems.

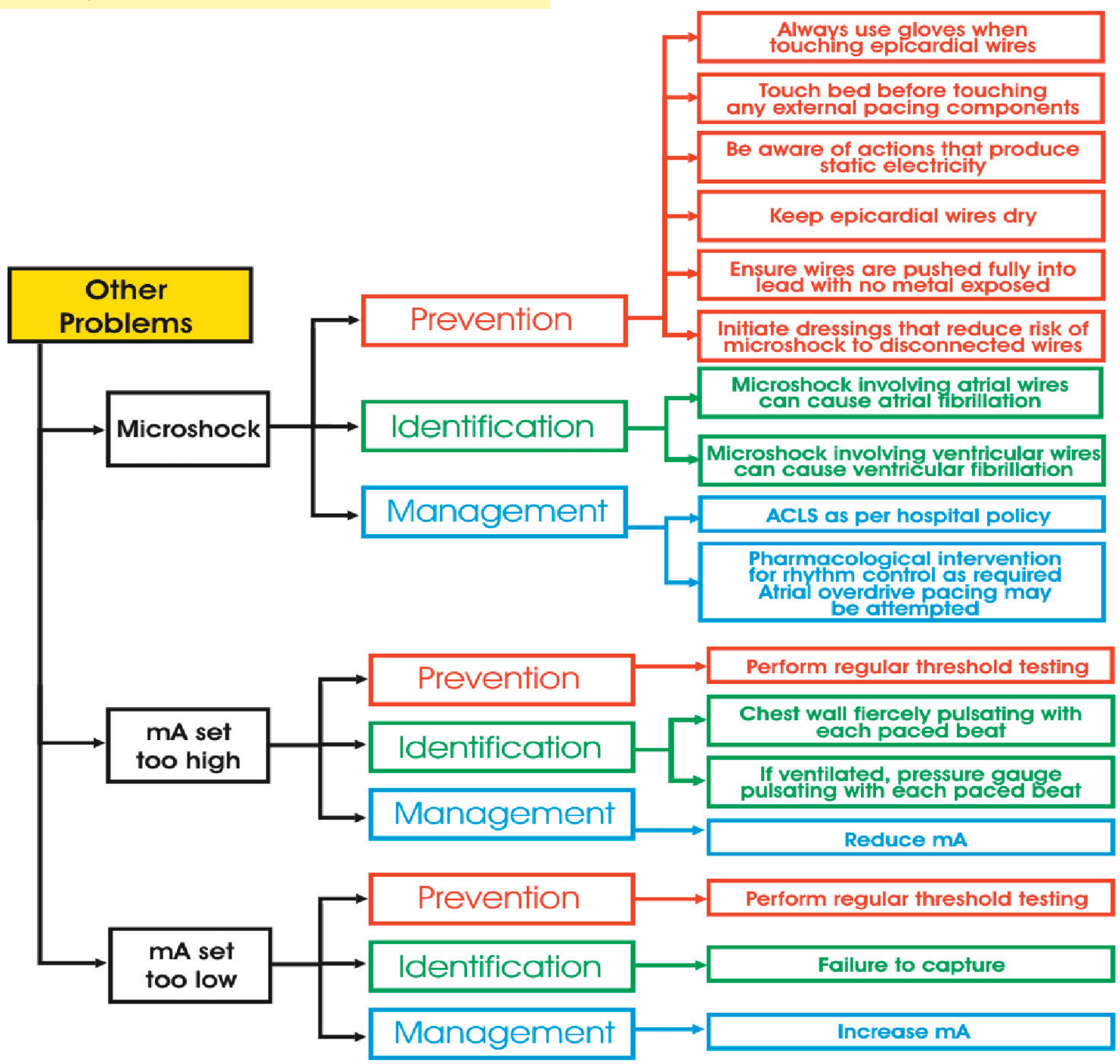

Figure 12: Summary of wire problems. 


\section{Prevention - microshock}

Microshock can be prevented by simple techniques to reduce the risk of static electricity coming into contact with the metal of the epicardial wires. These techniques include:

* Using gloves when touching the wires;

* Ensuring the epicardial wires are pushed into the lead so that no metal is exposed;

* Intensive care units with carpet have a higher risk of generating static electricity, so always touch the bed to discharge the current before you touch any external pacing component;

* Because water increases conduction, use dressing techniques that keep the disconnected wires dry.

\section{Identification - microshock}

Microshock can be identified as a type of ' $R$ on $T$ ' event on the cardiac monitor (Figure 13). Although any rogue electrical current delivered to the myocardium is dangerous, the most critical period is when the ventricle is repolarising.

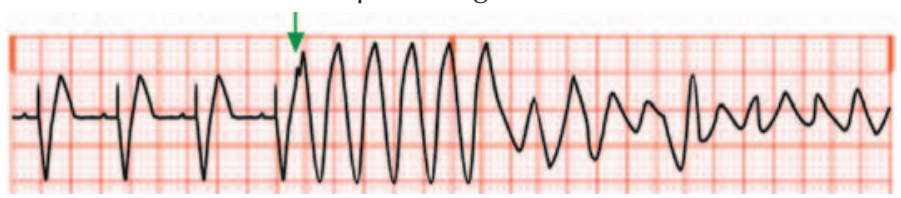

Figure 13: Example of an 'R on $\mathrm{T}^{\prime}$ caused by microshock.

As Figure 13 shows, there were four ventricular paced complexes before the microshock event (identified by the green arrow), followed by ventricular tachycardia (VT) which developed rapidly into ventricular fibrillation (VF).

\section{Management - microshock \\ Intervention will depend on the lead associated with the micro- shock. When an exogenous current (a current other than that delivered by the pulse generator) travels through the atrial wires, it could cause atrial fibrillation. If it passes through the ventricu- lar wires, it could mean ventricular tachycardia or fibrillation. In which case, the patient will need immediate resuscitative or rhythm control measures. Atrial overdrive pacing may resolve the atrial fibrillations, and direct current counter shock (DCCS) may be required for VT or VF.}

\section{Prevention - inappropriate $\mathbf{m A}$ (output) settings}

Initially, regular threshold testing will initially prevent inappropriate $\mathrm{mA}$ settings, although prolonged pacing does mean an increasing need for higher output settings. Elmi et al. (2002) showed that, following cardiac surgery, the reliability of both atrial and ventricular epicardial wires to gain capture, decreases daily. This results in the need to increase the $\mathrm{mA}$, contributing further to the rapid decline in the sensitivity of the myocardium. Using the minimum $\mathrm{mA}$ to gain effective capture may lead to less rapid injury to the myocardium.

\section{Identification - inappropriate $\mathbf{m A}$ (output) settings}

Inadequate $\mathrm{mA}$ will cause loss of capture and excessive $\mathrm{mA}$ may cause excessive movement of the patient's chest wall or, if the patient is ventilated, pulsation of the ventilator pressure gauge.

\section{Management - inappropriate mA (output) settings}

Regular threshold testing (according to unit/hospital protocol) and increasing the mA usually result in capture. Occasionally, however, loss of capture is not related to inadequate $\mathrm{mA}$. If, having eliminated all other potential causes (e.g. box, lead or wire problems) and the $\mathrm{mA}$ is set to the maximum 20, try swapping the polarity of the epicardial wires (Figure 14). Changing the polarity paces the myocardium in a slightly different area because the other electrode is now the cathode. An area of myocardium may now be responsive to the impulse. Failing this, other methods of rate and rhythm control will be needed.

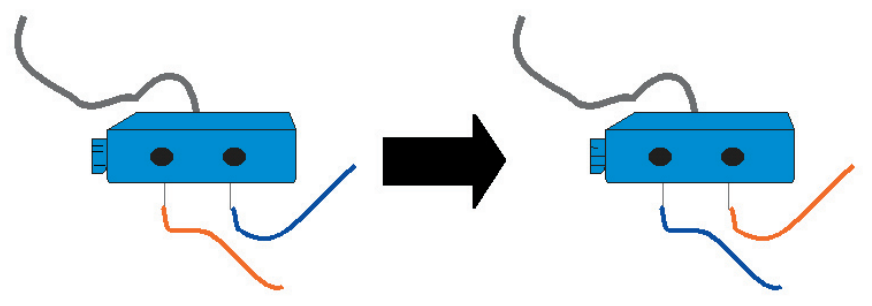

Figure 14: Swapping the polarity of epicardial wires may help to regain capture.

\section{CONCLUSION}

With so many possible issues related to equipment failure during temporary epicardial pacing, being familiar with methods to prevent, identify and manage these will ultimately result in a better outcome for the patient. This article has systematically reviewed these problems and offered information to prepare the novice nurse for experience with epicardial pacing.

\section{ACKNOWLEDGEMENTS}

The author appreciates the support from Ms Robin Fisher (Lecturer, Australian Catholic University) for her encouragement, intellectual debate and assistance with the manuscript.

\section{REFERENCES}

Chung M. (2000) Cardiac surgery: Postoperative arrhythmias. Critical Care Medicine 28 (10), (Suppl.) N136-N144.

Elmi F, Tullo N \& Khalighi K. (2002) Natural history and predictors of temporary epicardial pacemaker wire function in patients after open heart surgery. Cardiology 98 (4), 175-180.

Hurle A, Gomez-Plana J, Sanchez J, Martinez J, Meseguer J \& Llamas P. (2002) Optimal location for temporary epicardial pacing leads following open heart surgery. Pacing \& Clinical Electrophysiology 25 (7), 1049-1052.

Jefferies J, Younis G, Glamm S, Rasekh A \& Massumi A. (2005) Chest pain and diaphragmatic pacing after pacemaker implantation. Texas Heart Institute Journal 32 (1), 106-107.

Irwin M. (2004) Cardiac pacing device therapy for atrial dysrhythmias: how does it work? AACN Clinical Issues 15 (3), 377-390.

Jacobson C \& Gerity D. (2005) Pacemakers and implantable defibrillators. In: Woods S, Froelicher E \& Underhill Motzer S. (eds) Cardiac Nursing (5th ed). Philadelphia: Lippincott Williams \& Wilkins.

Medtronic. (2004) History of pacemakers: Technology development through the decades [online]. Available at: http://www.medtronic. com/brady/patient/pacemaker_history.htm/ [Last accessed: 14 May 2005].

Toquero B, Arroyo-Espliguero R \& Lozano I. (2003) Pacemaker lead displacement: Mechanisms and management [online]. Indian Pacing \& Electrophysiology Journal 3 (4), 231-238. Available at: http://www.ipej. org/0304/toquero.htm [Last accessed: 14 May 2005]. 